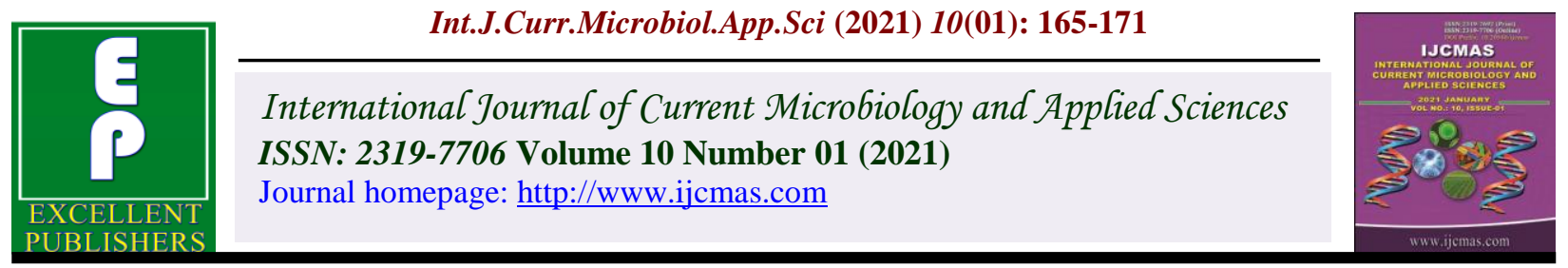

Original Research Article

https://doi.org/10.20546/ijcmas.2021.1001.019

\title{
Studies on Different Temperature Humidity Index Models in Relation with Monthly Milk Yield for HF × GIR Halfbreds
}

\author{
Ghoshita Suryakant Hingonekar*, Dilip Kundalik Deokar, Swapnali Uttamrao Rokade \\ and Harshavardhan Shahaji Sonawane
}
${ }^{1}$ Department of Animal Husbandry and Dairy Science, College of Agriculture, Dhule, Mahatma Phule Krishi Vidyapeeth, Rahuri, India

*Corresponding author

\section{A B S T R A C T}

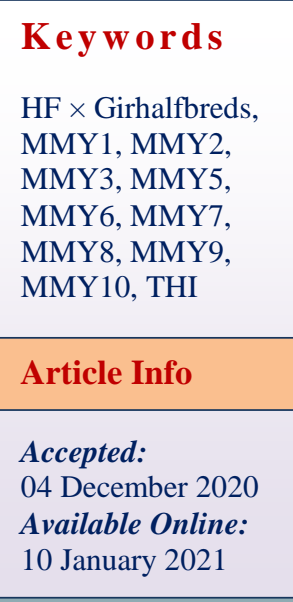

Keywords

HF $\times$ Girhalfbreds, MMY1, MMY2, MMY3, MMY5, MMY8, MMY9, MMY10, THI

\section{Introduction}

Increased pressure for intensified milk production and simultaneous rise in environmental temperature due to global warming has increased the thermal load on dairy animals. Elevated environmental temperature combined with high humidity causes discomfort and escalates the stress level in animals which is reflected in terms of reduced physiological and metabolic activities that results in reduced growth, drop in production and reproduction in farm animals.
The data on production performance of $\mathrm{HF} \times$ Girhalfbreds maintained at Research cum Development Project on Cattle (RCDP), Mahatma Phule Krishi Vidyapeeth, Rahuri district, Ahmednagar, (M.H) were utilized for present study. The least squares means of monthly milk yield $(\mathrm{kg})$ were estimated by considering the effects of period of calving, season of calving and lactation order as non-genetic factors. Then data were corrected for significant non genetic factor effect and effect of THI was estimated. The frequency distribution patterns for MMY according to THI were worked out. The THI had significant influence on MMY1, MMY3, MMY4 and MMY8 indicating that the $\mathrm{HF} \times$ Girhalfbreds were acclimatized to the local climate due to optimum feeding with sound management are provided. However, the THI had non-significant influence on, MMY2, MMY5, MMY6, MMY7, MMY9 and MMY10. 
strategies to combat heat stress includes selection of heat tolerant animals and their breeding, inclusion of heat tolerance as a trait while constructing selection index, providing balanced nutrition to the animals and implementation of good ventilation along with suitable cooling system in the farm(Behera et al., 2020).

\section{Materials and Methods}

The data of $\mathrm{HF} \times$ Girhalfbreds maintained at Research Cum-Development Project on Cattle, M.P.K.V., Rahuri for a period from 2009 to 2019 (10 years) were collected for present investigation for following Traits: a)Productive traits: 1) Total lactation milk yield (kg), 2) Lactation length (days), 3) Dry period (days), 4) Peak milk yield (kg).To examine the Production traits, the research data was classified into 3 periods of calving viz. $\quad \mathrm{P}_{1} \quad$ (2009-2011), $\quad \mathrm{P}_{2} \quad$ (2012-2014), $\mathrm{P}_{3}$ (2015above); 3 seasons of calving, viz. $\mathrm{S}_{1}$ (Rainy) June- September, $\mathrm{S}_{2}$ (Winter) October-January and $\mathrm{S}_{3}$ (Summer) FebruaryMay; 5 order of lactation viz. $\mathrm{L}_{1}$ first lactation, $\mathrm{L}_{2}$ second lactation, $\mathrm{L}_{3}$ third lactation, $\mathrm{L}_{4}$ fourth lactation, $\mathrm{L}_{5}$ fifth lactation; The effects of non-genetic factors like period of calving, season of calving and parity were estimated by using least-square analysis as suggested by Harvey (1990). The model was used with the assumption that different components being fitted into the model were as linear, independent and additive.

The model used was as follows:

\section{Model I}

$Y_{i j k l}=\mu+A_{i}+B_{j}+C_{k}+e_{i j k l}$

where $Y_{i j k l}$, observation of $1^{\text {th }}$ animal, $k^{\text {th }}$ parity, $j^{\text {th }}$ season of calving, $i^{\text {th }}$ period of calving; $\mu$ overall mean, $A_{i}$ fixed effect of $i^{\text {th }}$ period of calving ( 1 to 3 ), $B_{j}$ fixed effect of $j^{\text {th }}$ season of calving (1 to 3 ), $\mathrm{C}_{\mathrm{k}}$ fixed effect of $\mathrm{k}^{\text {th }}$ parity (1 to 5$) ; \mathrm{e}_{\mathrm{ijk} l}$ random error $\sim$ NID $(0$, $\left.\sigma^{2} e\right)$.

\section{Correction of data}

Whenever the effects found significant data were corrected and used for further analysis.

The data on different production traits were corrected for the significant effects of period of calving, season of calving and lactation order. The corrected data were used to find out the effect of THI on production traits.

\section{Temperature Humidity Index models}

Seven reported THI models were used to compute temperature humidity index as follows:

\section{THI models reference}

THI1 $=[0.4 \times(\mathrm{Tdb}+\mathrm{Twb})] \times 1.8+32+15$ Thom(1959)

THI2 $=(0.35 \times \mathrm{Tdb}+0.65 \times \mathrm{Twb}) \times 1.8+32$ Bianca (1962)

THI3 $=(0.15 \times \mathrm{Tdb}+0.85 \times \mathrm{Twb}) \times 1.8+32$ Bianca (1962)

THI $4=(\mathrm{Tdb}+\mathrm{Twb}) \times 0.72+40.6 \mathrm{NRC}$ (1971)

THI5 $=(0.55 \times \mathrm{Tdb}+0.2 \times \mathrm{Tdp}) \times 1.8+32$ +17.5 NRC (1971)

THI6 $=(1.8 \times \mathrm{Tdb}+32)-(0.55-0.0055 \times$ $\mathrm{RH}) \times(1.8 \times \mathrm{Tdb}-26.8) \mathrm{NRC}(1971)$

THI7 $=(0.8 \times \mathrm{Tdb})+[(\mathrm{RH} / 100) \times(\mathrm{Tdb}-$ 14.4) $]+46.4$ (Mader et al., 2006)

Tdb: dry bulb temperature; Twb: wet bulb temperature; RH: relative humidity; Tdp: dew 
point temperature. Tdb, Twb and Tdp were measured in ${ }^{\circ} \mathrm{C}$ and $\mathrm{RH}$ was measured in $\%$.

Monthly THI was computed using the environmental parameters and effect of THI was seen on traits under study by using following model.

\section{Model II}

$Y_{i j=} \mu+T_{H}+e_{i j}$

$\mathrm{Y}_{\mathrm{ij}}$ - Observation on $\mathrm{j}^{\text {th }}$ parameters for $\mathrm{i}^{\text {th }} \mathrm{THI}$ value range

$\mu$ - Overall mean

THI $I_{i}$ Effect of $i^{\text {th }}$ THI value range

$\mathrm{e}_{\mathrm{ij}}$ - Random error associated with NID $\sim(0$, $\sigma^{2}$ e) 7 different THI values as THI1 in 6 Ranges THI11 (71-74), THI12(74-77), THI13 (77-80), THI14 (80-83), THI15 (83-86), THI6 (86-89); THI2 in 5 Ranges THI21 (60-64), THI22 (64-68), THI23 (68-72), THI24 (7276), THI25 (76 -80); THI3 in 5 Ranges THI31 (58-62), THI32 (62-66), THI33 (66-70), THI34 (70-74), THI35 (74 -78); THI4 in 4 Ranges THI41 (65-69), THI42 (69-73), THI43 (73-77), THI44 (77-81); THI5 in 6 Ranges THI51 (72-75), THI52 (75-78), THI53 (78-81), THI54 (81-84), THI55 (8487), THI56 (87 -90); THI6 in 4 Ranges THI61 (65-70), THI62 (70-75), THI63 (75-80), THI64 (80-85); THI7 in 4 Ranges THI71 (6569), THI72 (69-73), THI73 (73-77), THI74 (77-81).

\section{Duncan's Multiple Range Test (DMRT)}

Duncan's Multiple Range Test as modified by Kramer (1957) was used to make pair wise comparison among the least square means with the use of inverse elements and root mean squares for error.
If the values:-

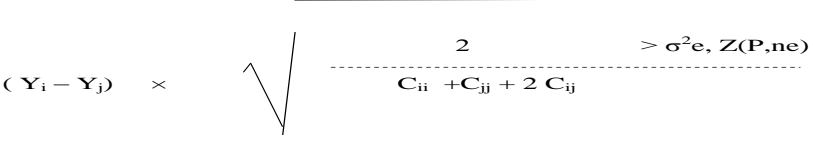

Where,

$Y_{i}-Y_{j}$ : Difference between two least squares means

$\mathrm{C}_{\mathrm{ii}}$ : Corresponding $\mathrm{i}^{\text {th }}$ diagonal elements of $\mathrm{C}$ matrix

$\mathrm{C}_{\mathrm{jj}}$ : Corresponding $\mathrm{j}^{\text {th }}$ diagonal elements of $\mathrm{C}$ matrix

$\mathrm{Z}$ ( $\mathrm{P}$, ne): Standardized range value in Duncan's table at the chosen level of probability for the error degrees of freedom

P: Number of means involved in the comparison

$\sigma^{2}$ e: Root mean squares for error

\section{Results and Discussion}

The overall least squares means for MMY 1 to MMY 10 are $406.19 \pm 11.94 \mathrm{~kg}, 383.11 \pm$ $15.38 \mathrm{~kg}, 340.52 \pm 19.03 \mathrm{~kg}, 291.32 \pm 12.53$ $\mathrm{kg}, 275.60 \pm 11.10 \mathrm{~kg}, 227.93 \pm 10.35 \mathrm{~kg}$, $203.29 \pm 10.04 \mathrm{~kg}, 177.40 \pm 7.22 \mathrm{~kg}, 151.19$ $\pm 10.06 \mathrm{~kg}$ and $134.71 \pm 11.26 \mathrm{~kg}$ respectively in $\mathrm{HF} \times$ Girhalfbreds.

\section{Effect of THI monthly milk yield first}

The overall least squares mean of monthly milk yield first in $\mathrm{HF} \times$ Girhalfbreds was $406.19 \pm 11.94 \mathrm{~kg}$.

According to the above investigation the effect of THI1 and THI7 on monthly milk yield first of $\mathrm{HF} \times$ Girhalfbreds, was significant (Table 1 and 2). 
Table.1 Least Square means of MMY 1 TO MMY 6 in HF×Girhalfbreds

\begin{tabular}{|c|c|c|c|c|c|c|c|c|c|c|c|c|}
\hline Effect & $\mathbf{N}$ & MMY1 & $\mathbf{N}$ & MMY2 & $\mathbf{N}$ & MMY3 & $\mathbf{N}$ & MMY4 & $\mathbf{N}$ & MMY5 & $\mathbf{N}$ & MMY6 \\
\hline$\mu$ & & $406.19 \pm 11.94$ & & $383.11 \pm 15.38$ & & $340.52 \pm 19.03$ & & $291.32 \pm 12.53$ & & $275.60 \pm 11.10$ & & $227.93 \pm 10.35$ \\
\hline THI11 & 9 & $388.98^{c} \pm 41.29$ & 10 & $432.02 \pm 39.69$ & 10 & $324.14 \pm 61.61$ & 8 & $274.25 \pm 37.40$ & 7 & $285.77 \pm 38.48$ & 5 & $210.60 \pm 43.77$ \\
\hline THI12 & 27 & $458.63^{\mathrm{a}} \pm 23.84$ & 29 & $356.95 \pm 23.31$ & 21 & $309.91 \pm 42.51$ & 28 & $312.97 \pm 19.99$ & 21 & $249.81 \pm 22.21$ & 22 & $231.10 \pm 20.86$ \\
\hline THI13 & 32 & $410.60^{b} \pm 21.89$ & 33 & $367.68 \pm 21.85$ & 35 & $363.06 \pm 32.93$ & 17 & $295.41 \pm 25.66$ & 31 & $253.01 \pm 18.28$ & 25 & $235.40 \pm 19.57$ \\
\hline THI14 & 52 & $354.86^{\mathrm{d}} \pm 17.17$ & 50 & $377.95 \pm 17.75$ & 44 & $343.96 \pm 29.37$ & 58 & $290.36 \pm 13.89$ & 58 & $255.40 \pm 13.36$ & 59 & $226.99 \pm 12.74$ \\
\hline THI15 & 40 & $426.31^{\mathrm{ab}} \pm 19.58$ & 44 & $373.46 \pm 18.92$ & 51 & $394.69 \pm 27.28$ & 54 & $311.14 \pm 14.39$ & 46 & $281.72 \pm 15.01$ & 43 & $238.18 \pm 14.92$ \\
\hline THI16 & 9 & $397.75^{b c} \pm 41.29$ & 3 & $390.60 \pm 72.47$ & 8 & $307.35 \pm 68.88$ & 4 & $263.80 \pm 52.90$ & 6 & $327.88 \pm 41.56$ & 13 & $225.31 \pm 27.14$ \\
\hline THI21 & 10 & $412.97 \pm 40.17$ & 11 & $419.74 \pm 37.81$ & 12 & $320.43 \pm 56.67$ & 9 & $290.28 \pm 35.30$ & 7 & $285.77 \pm 38.37$ & 7 & $228.68 \pm 36.85$ \\
\hline THI22 & 34 & $444.26 \pm 21.78$ & 35 & $363.37 \pm 21.20$ & 30 & $350.83 \pm 35.84$ & 32 & $311.74 \pm 18.72$ & 32 & $238.66 \pm 17.94$ & 25 & $236.09 \pm 19.49$ \\
\hline THI23 & 31 & $396.10 \pm 22.81$ & 27 & $362.34 \pm 24.13$ & 28 & $364.57 \pm 37.09$ & 20 & $309.83 \pm 23.68$ & 24 & $279.85 \pm 20.72$ & 27 & $222.58 \pm 18.76$ \\
\hline THI24 & 62 & $383.30 \pm 16.13$ & 59 & $380.46 \pm 16.32$ & 60 & $366.17 \pm 25.34$ & 69 & $291.28 \pm 12.75$ & 64 & $257.11 \pm 12.69$ & 69 & $226.58 \pm 11.73$ \\
\hline THI25 & 32 & $400.93 \pm 22.45$ & 37 & $371.40 \pm 20.62$ & 39 & $349.51 \pm 31.43$ & 39 & $302.40 \pm 16.95$ & 42 & $286.20 \pm 15.66$ & 39 & $242.02 \pm 15.61$ \\
\hline THI31 & 15 & $433.56 \pm 32.98$ & 16 & $391.25 \pm 31.29$ & 13 & $308.18^{d} \pm 52.89$ & 18 & $289.43^{\mathrm{bc}} \pm 24.21$ & 13 & $277.21 \pm 28.45$ & 11 & $247.32 \pm 29.22$ \\
\hline THI32 & 49 & $409.16 \pm 18.24$ & 41 & $395.32 \pm 19.55$ & 42 & $378.47^{b} \pm 29.42$ & 34 & $298.03^{\mathrm{ab}} \pm 17.62$ & 31 & $248.73 \pm 18.42$ & 37 & $240.21 \pm 15.93$ \\
\hline THI33 & 24 & $428.31 \pm 26.07$ & 33 & $357.60 \pm 21.79$ & 23 & $355.88^{b c} \pm 39.76$ & 15 & $384.72^{a} \pm 26.52$ & 22 & $272.53 \pm 21.87$ & 17 & $196.43 \pm 23.50$ \\
\hline THI34 & 59 & $387.58 \pm 16.63$ & 48 & $375.42 \pm 18.07$ & 68 & $317.71^{\mathrm{c}} \pm 23.12$ & 69 & $287.90^{c} \pm 12.36$ & 67 & $272.57 \pm 12.53$ & 67 & $230.04 \pm 11.84$ \\
\hline THI35 & 22 & $382.24 \pm 27.23$ & 31 & $355.42 \pm 22.48$ & 23 & $455.97^{a} \pm 39.76$ & 33 & $293.87^{b} \pm 17.88$ & 36 & $257.14 \pm 17.10$ & 35 & $235.00 \pm 16.38$ \\
\hline THI41 & 18 & $464.33 \pm 29.74$ & 22 & $405.15 \pm 26.63$ & 19 & $331.16 \pm 44.90$ & 26 & $295.06 \pm 20.67$ & 14 & $267.37 \pm 27.32$ & 14 & $249.78 \pm 26.00$ \\
\hline THI42 & 48 & $412.38 \pm 18.21$ & 49 & $356.06 \pm 17.84$ & 41 & $349.24 \pm 30.56$ & 27 & $307.68 \pm 20.29$ & 41 & $247.23 \pm 15.96$ & 33 & $228.81 \pm 16.93$ \\
\hline THI43 & 68 & $381.52 \pm 15.30$ & 59 & $374.75 \pm 16.26$ & 67 & $369.17 \pm 23.91$ & 77 & $290.81 \pm 12.01$ & 79 & $269.33 \pm 11.50$ & 80 & $228.20 \pm 10.87$ \\
\hline THI44 & 35 & $400.36 \pm 21.33$ & 39 & $380.43 \pm 20.00$ & 42 & $353.18 \pm 30.20$ & 39 & $315.53 \pm 16.88$ & 35 & $276.35 \pm 17.28$ & 40 & $232.04 \pm 15.38$ \\
\hline THI51 & 9 & $388.98 \pm 41.89$ & 15 & $368.86 \pm 32.66$ & 11 & $318.52 \pm 58.86$ & 9 & $286.17 \pm 35.37$ & 9 & $246.11 \pm 32.20$ & 8 & $231.32 \pm 34.61$ \\
\hline THI52 & 27 & $458.63 \pm 24.18$ & 24 & $380.79 \pm 25.82$ & 20 & $312.29 \pm 43.65$ & 27 & $310.43 \pm 20.42$ & 24 & $300.22 \pm 21.79$ & 19 & $225.61 \pm 22.46$ \\
\hline THI53 & 37 & $396.73 \pm 20.66$ & 34 & $366.07 \pm 21.69$ & 36 & $367.06 \pm 32.53$ & 21 & $288.69 \pm 23.16$ & 25 & $265.61 \pm 20.52$ & 29 & $232.76 \pm 18.17$ \\
\hline THI54 & 52 & $370.19 \pm 17.43$ & 55 & $374.94 \pm 17.05$ & 49 & $389.04 \pm 27.89$ & 62 & $296.51 \pm 13.47$ & 61 & $299.41 \pm 11.37$ & 61 & $230.06 \pm 12.53$ \\
\hline THI55 & 34 & $422.11 \pm 21.55$ & 38 & $378.84 \pm 20.52$ & 43 & $349.85 \pm 29.77$ & 45 & $309.32 \pm 15.82$ & 45 & $319.20 \pm 14.7$ & 36 & $239.22 \pm 16.31$ \\
\hline THI56 & 10 & $394.34 \pm 39.74$ & 3 & $390.60 \pm 73.03$ & 10 & $310.88 \pm 61.73$ & 5 & $270.84 \pm 47.46$ & 5 & $259.73 \pm 40.36$ & 14 & $218.02 \pm 26.16$ \\
\hline THI61 & 23 & $436.44 \pm 26.63$ & 31 & $378.14 \pm 22.58$ & 26 & $325.86 \pm 38.33$ & 24 & $324.76 \pm 36.33$ & 19 & $253.60 \pm 23.29$ & 14 & $229.84 \pm 26.04$ \\
\hline THI62 & 51 & $405.07 \pm 17.88$ & 42 & $366.56 \pm 19.40$ & 43 & $365.29 \pm 29.80$ & 47 & $355.29 \pm 31.80$ & 44 & $247.37 \pm 15.30$ & 44 & $228.90 \pm 14.69$ \\
\hline THI63 & 88 & $391.82 \pm 13.61$ & 93 & $376.53 \pm 13.04$ & 97 & $357.93 \pm 19.84$ & 95 & $357.57 \pm 20.84$ & 101 & $272.00 \pm 10.10$ & 100 & $231.65 \pm 9.74$ \\
\hline THI64 & 7 & $418.80 \pm 48.28$ & 3 & $390.60 \pm 72.60$ & 3 & $426.80 \pm 112.84$ & 3 & $420.70 \pm 110.84$ & 5 & $331.06 \pm 45.40$ & 9 & $236.78 \pm 32.48$ \\
\hline THI71 & 15 & $449.02^{\mathrm{a}} \pm 32.28$ & 21 & $359.71 \pm 27.42$ & 14 & $306.00 \pm 52.18$ & 17 & $282.55 \pm 25.64$ & 12 & $259.48 \pm 29.47$ & 8 & $231.32 \pm 34.36$ \\
\hline THI72 & 41 & $427.97^{\mathrm{ab}} \pm 19.52$ & 41 & $380.38 \pm 19.62$ & 40 & $356.05 \pm 30.87$ & 32 & $302.82 \pm 18.68$ & 38 & $251.83 \pm 16.56$ & 37 & $242.23 \pm 15.97$ \\
\hline THI73 & 68 & $367.77^{c} \pm 15.16$ & 64 & $372.31 \pm 15.70$ & 59 & $373.40 \pm 25.42$ & 69 & $297.54 \pm 12.72$ & 76 & $262.00 \pm 11.71$ & 72 & $223.72 \pm 11.45$ \\
\hline THI74 & 45 & $418.18^{b} \pm 18.63$ & 43 & $379.76 \pm 19.16$ & 56 & $350.40 \pm 26.09$ & 51 & $306.92 \pm 14.80$ & 43 & $284.52 \pm 15.56$ & 50 & $233.29 \pm 13.74$ \\
\hline
\end{tabular}


Table.2 Least Square means of MMY 7 TO MMY 10 in HF×Girhalfbreds

\begin{tabular}{|c|c|c|c|c|c|c|c|c|}
\hline Effect & $\mathbf{N}$ & MMY7 & $\mathbf{N}$ & MMY8 & $\mathbf{N}$ & MMY9 & $\mathbf{N}$ & MMY10 \\
\hline$\mu$ & & $203.29 \pm 10.04$ & & $177.40 \pm 7.22$ & & $151.19 \pm 10.06$ & & $134.71 \pm 11.26$ \\
\hline THI11 & 6 & $208.53 \pm 35.21$ & 8 & $183.62 \pm 26.09$ & 6 & $198.53 \pm 33.33$ & 8 & $141.45 \pm 30.21$ \\
\hline THI12 & 28 & $179.40 \pm 16.30$ & 20 & $169.78 \pm 16.50$ & 25 & $137.08 \pm 16.32$ & 22 & $130.94 \pm 18.22$ \\
\hline THI13 & 22 & $220.63 \pm 18.39$ & 25 & $189.91 \pm 14.76$ & 25 & $108.32 \pm 16.32$ & 17 & $132.00 \pm 20.73$ \\
\hline THI14 & 53 & $192.20 \pm 11.85$ & 43 & $158.36 \pm 11.25$ & 38 & $168.28 \pm 13.24$ & 37 & $131.71 \pm 14.05$ \\
\hline THI15 & 47 & $202.08 \pm 12.58$ & 43 & $201.33 \pm 11.25$ & 41 & $150.94 \pm 12.75$ & 28 & $120.79 \pm 16.15$ \\
\hline THI16 & 5 & $216.88 \pm 38.58$ & 12 & $161.43 \pm 21.30$ & 4 & $144.00 \pm 40.82$ & 3 & $151.36 \pm 49.34$ \\
\hline THI21 & 6 & $208.53 \pm 35.40$ & 9 & $187.11 \pm 25.07$ & 8 & $173.52 \pm 29.40$ & 11 & $144.38 \pm 25.39$ \\
\hline THI22 & 33 & $190.44 \pm 15.09$ & 28 & $172.75 \pm 14.21$ & 26 & $136.18 \pm 16.31$ & 27 & $119.54 \pm 16.20$ \\
\hline THI23 & 80 & $211.88 \pm 20.44$ & 17 & $191.14 \pm 18.24$ & 28 & $126.00 \pm 15.71$ & 11 & $165.96 \pm 25.39$ \\
\hline THI24 & 70 & $196.74 \pm 10.36$ & 55 & $170.09 \pm 10.14$ & 40 & $164.53 \pm 13.15$ & 45 & $128.05 \pm 12.55$ \\
\hline THI25 & 34 & $199.28 \pm 14.87$ & 42 & $187.87 \pm 11.60$ & 37 & $147.24 \pm 13.67$ & 21 & $122.00 \pm 18.38$ \\
\hline THI31 & 12 & $206.53 \pm 25.06$ & 12 & $181.43^{\mathrm{d}} \pm 21.16$ & 16 & $138.40 \pm 20.76$ & 14 & $153.81 \pm 22.61$ \\
\hline THI32 & 27 & $203.85 \pm 16.71$ & 31 & $180.79^{\mathrm{cd}} \pm 13.16$ & 32 & $147.53 \pm 14.68$ & 29 & $130.44 \pm 15.71$ \\
\hline THI33 & 21 & $189.19 \pm 18.94$ & 16 & $203.85^{\mathrm{ab}} \pm 18.32$ & 15 & $126.26 \pm 21.44$ & 10 & $121.16 \pm 26.76$ \\
\hline THI34 & 75 & $197.47 \pm 10.02$ & 65 & $160.00^{c} \pm 9.09$ & 48 & $167.20 \pm 11.99$ & 48 & $130.38 \pm 12.21$ \\
\hline THI35 & 26 & $197.36 \pm 17.02$ & 27 & $206.41^{\mathrm{a}} \pm 14.10$ & 28 & $129.67 \pm 15.69$ & 14 & $111.40 \pm 22.61$ \\
\hline THI41 & 21 & $204.16 \pm 18.82$ & 18 & $179.07 \pm 17.74$ & 20 & $140.03 \pm 18.63$ & 22 & $131.52 \pm 18.10$ \\
\hline THI42 & 29 & $185.47 \pm 16.02$ & 33 & $186.31 \pm 13.10$ & 33 & $128.86 \pm 14.50$ & 25 & $134.51 \pm 16.98$ \\
\hline THI43 & 73 & $195.52 \pm 10.09$ & 58 & $172.30 \pm 9.88$ & 52 & $161.61 \pm 11.55$ & 49 & $126.97 \pm 12.13$ \\
\hline THI44 & 38 & $209.41 \pm 13.99$ & 42 & $182.17 \pm 11.61$ & 34 & $147.92 \pm 14.29$ & 19 & $130.94 \pm 19.48$ \\
\hline THI51 & 10 & $177.72 \pm 27.34$ & 9 & $176.64 \pm 25.02$ & 6 & $198.53 \pm 33.37$ & 10 & $144.96 \pm 27.03$ \\
\hline THI52 & 24 & $187.38 \pm 17.65$ & 19 & $172.35 \pm 17.22$ & 25 & $137.08 \pm 16.34$ & 20 & $128.14 \pm 19.11$ \\
\hline THI53 & 23 & $220.67 \pm 18.03$ & 25 & $189.91 \pm 15.01$ & 28 & $114.20 \pm 15.44$ & 18 & $135.58 \pm 20.15$ \\
\hline THI54 & 56 & $196.50 \pm 11.55$ & 49 & $170.66 \pm 10.72$ & 41 & $170.68 \pm 12.76$ & 41 & $126.10 \pm 13.35$ \\
\hline THI55 & 41 & $196.36 \pm 13.50$ & 35 & $194.60 \pm 12.68$ & 35 & $145.60 \pm 13.81$ & 22 & $131.14 \pm 18.22$ \\
\hline THI56 & 7 & $213.20 \pm 32.68$ & 14 & $159.34 \pm 20.06$ & 4 & $144.00 \pm 40.87$ & 4 & $114.42 \pm 42.75$ \\
\hline THI61 & 27 & $188.85 \pm 16.63$ & 22 & $181.33 \pm 16.09$ & 21 & $158.11 \pm 17.96$ & 25 & $128.73 \pm 16.93$ \\
\hline THI62 & 31 & $206.70 \pm 15.52$ & 31 & $181.38 \pm 13.55$ & 41 & $119.73 \pm 12.85$ & 25 & $140.38 \pm 16.93$ \\
\hline THI63 & 98 & $197.00 \pm 8.73$ & 90 & $177.20 \pm 7.95$ & 73 & $160.00 \pm 9.63$ & 62 & $125.54 \pm 10.75$ \\
\hline THI64 & 5 & $216.88 \pm 38.65$ & 8 & $181.95 \pm 26.68$ & 4 & $144.00 \pm 41.15$ & 3 & $151.36 \pm 48.89$ \\
\hline THI71 & 8 & $227.30 \pm 33.34$ & 17 & $177.25 \pm 18.05$ & 12 & $161.78 \pm 23.91$ & 18 & $144.47 \pm 19.92$ \\
\hline THI72 & 34 & $222.00 \pm 14.45$ & 33 & $182.58 \pm 12.95$ & 37 & $122.25 \pm 13.62$ & 28 & $124.18 \pm 15.97$ \\
\hline THI73 & 69 & $209.12 \pm 12.40$ & 48 & $161.99 \pm 10.74$ & 48 & $159.57 \pm 11.95$ & 41 & $134.25 \pm 13.20$ \\
\hline THI74 & 50 & $217.25 \pm 12.89$ & 53 & $192.49 \pm 10.22$ & 42 & $151.47 \pm 12.78$ & 28 & $120.84 \pm 15.97$ \\
\hline
\end{tabular}


The differences in the monthly milk yield first of $\mathrm{HF} \times$ Girhalfbreds in THI12 significantly higher than THI 15, THI 13 and THI 16 were at par to each other. The effect of THI71 significantly higher than THI72, THI74 and THI73 were at par to each other.

The maximum monthly milk yield first in THI1, within range 2 i.e., THI 12 (458.63 \pm 23.84) and in THI7, within range 1 i.e., THI71 (449.02 \pm 32.28) and minimum monthly milk yield first in THI 14 (354.86 \pm 17.17) and in THI7, within range 3 i.e., THI73 (367.77 \pm 15.16$)$.

\section{Effect of THI monthly milk yield second}

The overall least squares mean of monthly milk yield second in $\mathrm{HF} \times$ Girhalfbreds was $383.11 \pm 15.38 \mathrm{~kg}$. According to the above investigation the effect of none of the THI was significant on monthly milk yield second of HF $\times$ Girhalfbreds.

\section{Effect of THI monthly milk yield third}

According to the above investigation the effect of THI3 on monthly milk yield third of $\mathrm{HF} \times$ Girhalfbreds, was significant. The differences in the MMY3 in THI 35 significantly higher than THI32, THI 33 and THI 34 and THI 31. The differences in THI32, THI33, THI34 and THI31 were at par eachother.

The maximum monthly milk yield third in THI3 within the range 5 i.e., THI35 (455.97 \pm 39.76) and minimum monthly milk yield third in THI 31 (308.18 \pm 52.89$)$.

\section{Effect of THI monthly milk yield fourth}

The overall least squares mean of monthly milk yield fourth in $\mathrm{HF} \times$ Girhalfbreds was $291.32 \pm 12.53 \mathrm{~kg}$. According to the above investigation the effect of THI3 on monthly milk yield fourth of HF $\times$ Girhalfbreds, was significant. The differences in the monthly milk yield fourth of $\mathrm{HF} \times$ Girhalfbreds in THI 33 significantly higher than THI 32, THI 35 and THI 31.The differences in the monthly milk yield fourth of $\mathrm{HF} \times$ Girhalfbreds in THI 32 and THI 35 and THI 31 were at par to each other. The maximum monthly milk yield fourth in in THI3 within the range 3 i.e., THI 33 (384.72 \pm 26.52$)$ and minimum monthly milk yield fourth in THI $34(287.90 \pm 12.36)$.

\section{Effect of THI monthly milk yield fifth}

The overall least squares mean of monthly milk yield fifth in $\mathrm{HF} \times$ Girhalfbreds was $275.60 \pm 11.10 \mathrm{~kg}$. According to the above investigation the effect of none of the THI was significant on monthly milk yield fifth of $\mathrm{HF} \times$ Girhalfbreds.

\section{Effect of THI monthly milk yield sixth}

The overall least squares mean of monthly milk yield sixth in $\mathrm{HF} \times$ Girhalfbreds was $227.93 \pm 10.35 \mathrm{~kg}$. According to the above investigation the effect of none of the THI was significant on monthly milk yield sixth of $\mathrm{HF} \times$ Girhalfbreds.

\section{Effect of THI monthly milk yield seventh}

The overall least squares mean of monthly milk yield seventh in $\mathrm{HF} \times$ Girhalfbreds was $203.29 \pm 10.04 \mathrm{~kg}$. According to the above investigation the effect of none of the THI was significant on monthly milk yield seventh of HF $\times$ Girhalfbreds.

\section{Effect of THI monthly milk yield eighth}

The overall least squares mean of monthly milk yield eighth in $\mathrm{HF} \times$ Girhalfbreds was $177.40 \pm 7.22 \mathrm{~kg}$. According to the above investigation the effect of THI3 on monthly milk yield eighth of $\mathrm{HF} \times$ Girhalfbreds, was 
significant. The differences in the MMY3 in THI 35 significantly higher than THI33, THI 31 and THI 32 and THI 34. The differences in THI35, THI33, THI31 and THI32 were at par each other. The maximum monthly milk yield eighth in THI3 within range 5 i.e., THI35 (206.41 \pm 14.10$)$ and minimum monthly milk yield eighth in THI $31(181.43 \pm 21.16)$.

\section{Effect of THI monthly milk yield ninth}

The overall least squares mean of monthly milk yield ninth in $\mathrm{HF} \times$ Girhalfbreds was $151.19 \pm 10.06 \mathrm{~kg}$. According to the above investigation the effect of none of the THI was significant on monthly milk yield nineth of $\mathrm{HF} \times$ Girhalfbreds.

\section{Effect of THI monthly milk yield tenth}

The overall least squares mean of monthly milk yield tenth in $\mathrm{HF} \times$ Girhalfbreds was
$134.71 \pm 11.26 \mathrm{~kg}$. According to the above investigation the effect of none of the THI was significant on monthly milk yield tenth of $\mathrm{HF} \times$ Girhalfbreds .

\section{References}

Behera R.,Mandal A.,Rai S., Karunakaran M. and Mondal M. (2020). Temperature Humidity Index and it's relationship with production traits of dairy cattle and buffaloes - Review. International Journal of Livestock Research, 10(3): 38-48.

Harvey W.R. (1990). Least-squares analysis of data with unequal subclass numbers. ARS H-4, U.S.D.A, Washington.

Kramer, C.V. (1957). Extension of multiple range test to group correlated adjusted mean. Biometrics, 13: 13-20.

\section{How to cite this article:}

Ghoshita Suryakant Hingonekar, Dilip Kundalik Deokar, Swapnali Uttamrao Rokade and Harshavardhan Shahaji Sonawane. 2021. Studies on Different Temperature Humidity Index Models in Relation with Monthly Milk Yield for HF $\times$ GIR Halfbreds. Int.J.Curr.Microbiol.App.Sci. 10(01): 165-171. doi: https://doi.org/10.20546/ijcmas.2021.1001.019 